\title{
Technological Solutions for Renewable Energy (Automation, Blockchain, and Smart Cities)
}

\author{
Anna Tarasova ${ }^{1, *}$ Olga Sutyrina $^{1}$, Raisa Krayneva ${ }^{2}$ \\ ${ }^{I}$ Volga State University of Technology, Yoshkar-Ola, Russia \\ ${ }^{2}$ Financial University under the Government of the Russian Federation, Moscow, Russia \\ "Corresponding author. Email: tarasovaan@volgatech.net
}

\begin{abstract}
A number of countries are projecting to ratify the idea of smart city in their towns and accomplish big data projects to bolster smart city features to target the desired level of sustainable development, thus improving the quality of life. The smart cities are meant to be areas with advanced technologies that are capable to comprehend the environment by scrutinizing the data so to make it more sustainable. In such cities various sensors will be gathering massive of data to learn critical measurements to control resources, services and infrastructure effectively. Numerous innovations, such as automation and blockchain will serve to increase the efficiency of its residents ways of travelling, educating, spending resources, thus resulting in higher level of comfort. This paper presents a comprehensive overview of the technological solutions and how those can be employed for smarter green energy use.
\end{abstract}

Keywords: blockchain, smart city, technological solution, green initiative.

\section{INTRODUCTION}

The proliferation of renewable energy sources can be accelerated by innovative technologies such as automation, artificial intelligence and blockchain, as well as advanced materials management and manufacturing operations [1]. Such innovations range from technologies that optimize the production of energy and the operation of RES assets (automation, advanced production technologies), to technologies that contribute to the more efficient use of RES (AI solutions for meteorological forecasts), improve the efficiency of the RES market (blockchain) and the transition for advanced materials for solar panels and wind turbines (advanced materials) [2].

These technologies help reduce costs and integrate more efficiently renewable energy into the grid. Automation can significantly reduce the financial and time costs of operating renewable energy assets and generating electricity [3]. Last year First Solar automated processes at its US solar power plant, thus tripling the size of the solar panels used. By transforming a complex multi-day process into a process that only takes a few steps and a few hours, the company has achieved an energy cost indicator that is $30 \%$ lower than of its competitors. Moreover, automation has a significant positive impact on offshore wind turbines, which account for more scheduled maintenance outages per $\mathrm{GW}$ of installed capacity than any other type of installation. The world's largest offshore wind farm introduced fully automated drones to its processes, hence decreasing the duration of technical inspections from two hours to 20 minutes. In the future, thanks to crawling robots, which are currently being developed, it may become possible to automate microwave and ultrasonic checks of the internal structure and materials of solar panels and wind turbines. Automated processes collect datasets that can be further analysed by AI to provide predictions and guidance [4].

Artificial intelligence technologies can improve the accuracy of weather forecasts and thereby optimize the use of renewable energy resources. Meteorological forecasts are a key component of the integration of renewable energy sources, since it is weather conditions that determine the availability of wind and solar resources, as well as the volumes of their consumption. On a cold, windy day, the supply and demand of wind power may increase, while on a windy night, supply may increase while the demand may remain unchanged. A system based on artificial intelligence can process images from satellites, the results of measurements made by weather stations, statistical data and detailed data coming from sensors 
to wind turbines and solar power plants. The analysis results can be used to predict weather conditions, compare forecast and actual data, and adjust the used model using machine learning algorithms to improve the accuracy of forecasts. AI systems can process hundreds of terabytes of data and generate detailed forecasts on a regular basis. National Meteorological Services in leading solar and wind energy markets have already deployed artificial intelligence technologies, resulting in significant improvements in forecast accuracy and cost savings for energy companies [5]. Thus, Spain's national AI-powered Sipreolico wind forecasting system has helped halve the number of errors in daily forecasts in seven years. Hyperlocal AI models for weather forecasting can now be deployed anywhere in as little as one week [6]. In addition, IBM is working with the US National Center for Atmospheric Research to create the first global meteorological model to bring AI technology to underdeveloped markets [7].

Another technology that can be useful in undercovered markets is blockchain. The power sector is rife with opportunities for blockchain applications. One of the most obvious uses for this technology is in the US Energy Attribute Certificates (EACs) market, as well as the European Energy Certificate (EEC) market. The concept behind the EAC is rather simple: each certificate confirms the production of $1 \mathrm{MW}$ of electricity intended for sale to consumers. However, the process of tracking electricity production itself is complex, and associated with high financial and time costs for many parties and is also subject to the risk of fraud. The use of blockchain gives organizations access to a shared, reliable inventory of all transactions carried out and eliminates the need for intermediaries such as registrars, brokers and approvers [8]. Automation of processes ensures transparency, low cost and speed of operations and is available even to small players. Using blockchain can also help eliminate many of the problems associated with bureaucracy and lack of trust. These problems are especially acute in developing countries, where they still have not been able to get the targeted audience off the ground [9]. Both new and established companies have already begun to analyze the capabilities of blockchain managing systems.

Cutting-edge materials and manufacturing technologies are Perovskite and 3D printing have the potential to revolutionize the solar and wind energy. The technology of obtaining solar energy using perovskite has been developing at a record pace since its inception. In less than 10 years, this mineral has provided such an increase in the efficiency of solar cells, which took more than half a century to achieve with the help of silicon [10]. In laboratory tests, perovskite was used in conjunction with silicon, breaking the previous laboratory record achieved with silicon alone [11]. The properties of perovskite are as follows: it is capable of converting a wider range of the light spectrum into electricity than silicon, and with greater efficiency. Additionally, perovskite can be sprayed onto a variety of surfaces or printed on rolls, which expands its applicability and reduces manufacturing costs. When it comes to wind energy, additive manufacturing technologies create opportunities for new materials. Thus, two national laboratories in the United States have teamed up with representatives of the energy sector in order to create, for the first time in history, a blank for threedimensional printing of a wind turbine blade. This will help to reduce significantly the financial and time costs for the production of blades. The next frontier will be direct $3 \mathrm{D}$ printing of blades, which will allow the use of new combinations of materials and embedded sensors to optimize costs and productivity, as well as manufacture blades at the location of the plant in order to eliminate logistics costs and risks. Manufacturers plan to start by 3D printing spare parts upon request at the location of the wind turbines. This will reduce costs and reduce downtime due to repairs [12].

\section{MATERIALS AND METHODS}

The authors address the issues of using various technologies to build and maintain smart city, through improving the travel, fitness, education and other services, thus contributing into a better quality of life. The empirical basis of this study includes the results of a secondary analysis of the research data covering the cutting-edge materials and manufacturing technologies, such as 3D printing, blockchain, artificial intelligence for renewable energy.

The article also discusses the opportunities for the cities to start up and successfully implement the green initiatives. Such strategic programs can be initiated by the citizens themselves and further sponsored by electronic giants, as in case of Pena Station Next Denver's Smart City Community. Companies such as Xcel Energy and Panasonic are key stakeholders in the Pena Station Next smart city project. The National Renewable Energy Laboratory is supporting the initiative and encourages it to be a net zero energy infrastructure. The paper also covers other counties' initiatives to adopting the idea of smart city in their metropolitan cities and implementing extensive data projects that promote smart city features to achieve the favoured level of sustainable development to improve the quality of life.

\section{RESULTS AND DISCUSSIONS}

The constant growth in demand for renewable energy is driven by cities, communities, emerging markets and corporations that are constantly looking for affordable, green and reliable energy sources. Thanks 
to the trends driving its development, solar and wind energy is now optimally equipped to meet all these needs. Renewable smart cities see such needs as an integral part of their strategies. The use of renewable energy sources in municipal energy expands consumers' access to electricity or increases the number of energy supply options available to them. Emerging markets are using solar and wind energy as the best tool for implementing their development strategies. Corporations purchase renewable energy to improve profits and sustainability of their operations [13].

The administration of renewable smart cities understands that use of wind and solar energy can help achieve their strategic goals. Today, most of the world's population lives in growing cities, some of which take proactive, sustainable approaches to urban infrastructure management using an integrated network of sensors and data analysis. More advanced smart city administrations focus on improving the quality of life, competitiveness and sustainability [14,15,16]. Solar and wind power is at the intersection of these goals, as it helps reduce pollution and carbon dioxide emissions and increase the resilience of energy grids, while ensuring green mobility, economic development and business growth. Renewable energy smart cities benefit from such interconnection, the largest of the cities try to transform the existing infrastructure, or create brandnew ones by building from a scratch.

A smart city is a city with solar or wind power and a development plan that includes a renewable energy component. The list of the largest "smart" cities using renewable energy (Table 1) includes cities with a population of over 1 million people in terms of the share of renewable energy in the total energy balance. The world leader is San Diego. Solar-wind energy already accounts for more than a third of the city's total energy balance, and by the year of 2035 San Diego should switch to renewable energy to the full. San Diego's renewable energy initiatives come from the city itself. The US government is now moving away from its commitments to tackle climate change, while San Diego, by contrast, is committing itself to continue to roll out renewables. Moreover, San Diego's RES share targets are so ambitious that they exceed those for the state of California as a whole [17]. Meanwhile, Jaipur, the leading city in Asia, is implementing a strategy for the introduction of renewable energy with the support of the state. The Indian government has developed an initiative to create 100 smart cities in the country, which, among other things, should be using the solar energy [18]. There is no separate renewable energy target for Jaipur, but the city will undoubtedly benefit from the ambitious plans set for individual states and for the country as a whole. A key solar energy initiative in Jaipur is improving the city's energy infrastructure with solar panels on rooftops. This technology will be applied to eight metro stations, which in the daytime will be supplied with energy exclusively from solar panels. Another example of a cosmopolitan smart city, Hamburg, the European market leader, implements renewable energy initiatives at both local and federal levels. When it comes to smart cities, Germany is among the lagging European countries because it does not have a national strategy in this area and does not seek to expand access to funding for such projects. However, the European Union provides a variety of platforms and funding sources to support initiatives aimed at building smart cities using renewable energy [19]. Thus, Hamburg has successfully leveraged these platforms and sources not only to introduce renewable energy, but also to gain a reputation as a European hub for researchers and companies working in the renewable energy sector [20,21]. All these smart cities are faced with the challenge of transforming existing infrastructure and systems in order to improve their efficiency and increase the share of renewable energy in the overall energy balance.

Brand-new smart cities are not burdened with outdated infrastructure, vested interests and bureaucratic barriers, and therefore can build exemplary structures, testing and demonstrating the latest technologies in action. For example, Pena Station Next is an aerotropolis seeking to take advantage of its strategic location. Pena Station Next is located at the train station between the thriving city of Denver and its growing airport, which are key stakeholders in the smart city project. The city covers an area of 382 acres and is powered by a self-contained micro-system of

Table 1. The largest renewable energy smart cities.

\begin{tabular}{|l|c|c|}
\hline \multicolumn{1}{|c|}{ City } & Population (mill of people) & Share of solar and wind energy in the total electricity generated per year (\%) \\
\hline San Diego & 1.4 & 33 \\
\hline Los Angeles & 1 & 20 \\
\hline Jaipur & 3 & 20 \\
\hline Hamburg & 1.8 & 14.8 \\
\hline Toronto & 2.8 & 12 \\
\hline Bangalore & 11 & 10 \\
\hline Santiago & 7.3 & 9 \\
\hline Seoul & 10.3 & 6.6 \\
\hline Tainan & 1.9 & 5.1 \\
\hline Paris & 2.3 & 4.2 \\
\hline
\end{tabular}


solar panels and electricity storage. The system is owned by Xcel Energy and operated by Panasonic. Both of these companies are key stakeholders in the Pena Station Next smart city project. The project is also partnering with the National Renewable Energy Laboratory (NREL), which is helping the city achieve net zero energy (i.e. consuming no more energy than it produces itself) and developing a plan for an integrated, carbon-neutral utility infrastructure development plan.

In Canada, on the territory of the Toronto metropolis, the Quayside smart city project is being implemented from scratch, which is one of the top ten smart cities powered by renewable energy sources. Solar panels on the roofs and walls of the buildings will power the 800-acre coastal area. The project partner is Alphabet's Sidewalk Labs. Moreover, the Crown Prince of Saudi Arabia announced a \$ 500 billion NEOM smart city project. The city of 10,000 acres will be located on the shores of the Red Sea. Its goal is to become an international center equal in importance to Dubai [22]. It is planned that the city will operate exclusively at the expense of solar power plants and wind turbines with energy storage facilities and connect with Egypt using a sea bridge. The first generation of zero-cycle smart cities has been criticized. They were called "ghost towns" as more attention was paid to technology than to residents of such huge projects. However, the new generation of smart cities is striving for harmonious integration with the already existing urban infrastructure. A good example of the latter can be Denver, Pena Station that is a user-centric innovation ecosystem.

Quayside serves as Toronto's model for sustainable development. NEOM serves as the center of communication between Asia and Africa. An integral part of such projects is the use of solar and wind energy. Despite their modest size, Pena Station and Quayside provide evidence for the feasibility of applying their underlying technology concepts and business models, which can then be scaled up to larger cities. In the case of NEOM, conceptualization can be done on a much larger scale. Given this level of freedom, the challenge for greenfield smart cities is to narrow the options down to a combination worth considering. Renewable energy projects for new cities are also of great importance for areas that cannot be served by centralized power grids.

\section{CONCLUSIONS}

There is a trend to use solar energy in municipal energy. The concept of public utilities renewable energy also includes the use of energy storage and energy management systems that provide more flexibility. This evolution has led to the emergence of new ways of using the generated energy to serve the territories located both in the coverage area of the centralized power grid and beyond. This approach can assist in the electrification of areas not covered by a centralized power grid, while the price and performance will be comparable to those of other energy sources. As for the territories in the coverage area of the power grid, this approach allows for independent power supply, ensuring the stability of the functioning and independence of the power system.

Many countries have switched to renewable utilities both within the coverage area of traditional power grids and beyond, as this simplifies access to the benefits of renewable energy sources. In areas not served by centralized power grids, renewable utilities can provide optimal electrification. In relation to such zones, the concept of renewable public utilities energy can be defined as the creation of partnerships with the participation of local communities for the electrification of the respective territories and the reinvestment of the resulting profits in their development. Such projects involve mainly the creation of small power systems (micro-power systems) in rural areas with a sufficient population density. These systems consist of solar panels and energy storage. The main driving factor for the development of solar microsystems is their cost effectiveness compared to fossil fuel microsystems, expansion of the existing power grid, kerosene lamps or diesel generators. Moreover, in developing countries, RES microsystems tend to be more reliable than centralized power grids. Renewable public utilities energy projects are in most cases initiated and funded by non-governmental organizations (NGOs). The advantage of renewable energy utilities over other electrification models is that such a scheme resonates well with the local population and empowers them. Equally clear are the benefits for many geographically isolated and remote areas in developed countries.

On the other hand, some communities in developed countries are adopting renewable utilities in order to be able to disconnect from the centralized grid. In particular, this applies to Australia, where in 2017 there was a sharp surge in the popularity of utility power systems based on renewable energy sources. Due to the high cost and low reliability of the services of the national power grid, which mainly uses coal-fired CHP plants, a number of settlements are developing their own autonomous micro-grids, operating from renewable energy sources. These micro grids can sell the surplus generated electricity to the centralized grid or disconnect from it altogether.

The most common structure is called energy cooperatives, which are based on the joint ownership of renewable energy resources. Such resources are owned and operated jointly. Germany is the world leader in the energy cooperative market: more than $40 \%$ of the renewable energy capacities installed in the country last year are objects of cooperative property. The creation 
of energy cooperatives in developed countries contributed to a more active participation of citizens in projects for the introduction of renewable energy sources and their popularization among the population.

In the United States, energy cooperatives are also pioneers in the renewable energy sector. In the United States, power systems owned and operated by cooperative members account for more than $70 \%$ of total solar utility projects, while large utilities account for the bulk of the capacity. Nearly half of US households and businesses cannot use solar panels due to the lack of suitable or easily accessible rooftop space. The renewable utility model allows them to buy electricity from a shared renewable power plant and receive corresponding deductions on bills for electricity supplied by conventional energy companies. Twothirds of the renewable energy utilities in the United States are operated by third-party suppliers serving primarily commercial customers based primarily in Colorado, Minnesota, and Massachusetts, and another third are directly operated by power grids that serve primarily private customers. The low cost of renewable energy, consumer interest in renewable energy sources and concerns about ensuring the sustainability of energy systems are driving a strong demand for renewable utilities. Many communities already facing blackouts caused by natural disasters or severe weather are turning to small renewable energy grids as a tool to keep electricity supplies stable and protect critical infrastructure. This is the case in Japan, where a national sustainability plan has been developed to support renewable utilities. Despite the growing role of cities and local communities in the introduction of solar and wind energy in developed markets, national initiatives are most relevant to emerging markets.

\section{ACKNOWLEDGMENTS}

The research was supported by the Ministry of Science and Higher Education of the Russian Federation (Grant № 075-15-2021-674) and Core Facility Centre «Ecology, biotechnologies and processes for obtaining environmentally friendly energy carriers» of Volga State University of Technology, Yoshkar-Ola.

\section{REFERENCES}

[1] M. Afzal, Q. Huang, W. Amin, K. Umer, A. Raza and M. Naeem, IEEE Access, 8 (2020) p. 37428.

[2] M. J. Ashley, M. S. Johnson, IEEE Engineering Management Review, 46(4) (2018) p. 100.

[3] Y.-C. Tsao, V.-V. Thanh, Renewable Energy, 163 (2021) p. 870.

[4] J.-S. Chou, D.-S. Tran, Energy, 165 (B) (2018) p. 709.
[5] F. Rodríguez, A. M. Florez-Tapia, L. Fontán, A. Galarza, Renewable Energy, 145 (2020) p. 1517.

[6] H. Wang, Y. Liu, B. Zhou, C. Li, G. Cao, N. Voropai, E. Barakhtenko, Energy Conversion and Management, 214 (2020) p. 112909.

[7] M. L. Conde, I. Twinn, EMCompass, 75 (2019).

[8] M.M. Queiroz, R. Telles, S.H. Bonilla, Supply Chain Management, 25(2) (2019) p. 241

[9] S. Modgil, S. Gupta, U Sivarajah, B. Bhushan, Technological Forecasting and Social Change, 166 (2021) p. 120607.

[10] S.A. Olaleru, J.K. Kirui, D. Wamwangi, K.T. Roro, B. Mwakikunga, Solar Energy, 196 (2020) p. 295 .

[11] W. Ke, C. C. Stoumpos, M. Zhu, L. Mao, I. Spanopoulos, J. Liu, O. Y. Kontsevoi, M. Chen, D. Sarma, Y. Zhang, M. R. Wasielewski, M. G. Kanatzidis, Science Advances, 3(8) (2017) p. 701293.

[12] B. Wittbrodt, J. M. Pearce, Energy for Sustainable Development, 36 (2017) p. 1.

[13] Z. Peidong, Y. Yanli, Shi jin, Z. Yonghong, W. Lisheng, L. Xinrong, Renewable and Sustainable Energy Reviews, 13(2) (2009) p. 439.

[14] M. Farmanbar, K. Parham, Ø. Arild, C. Rong, Energies, 12 (2019) p. 4484.

[15] J.Z. Thellufsen, H. Lund, P. Sorknæs, P.A. Østergaard, M. Chang, D. Drysdale, S. Nielsen, S.R. Djørup, K. Sperling, Renewable and Sustainable Energy Reviews, 129 (2020) p. 109922.

[16] N. Javaid et al., IEEE Access, 5 (2017) p. 13587.

[17] M. Agbali, C. Trillo, I.A. Ibrahim, Y. Arayici, T. Fernando, T. Smart Cities, 2 (2019) p. 307.

[18] S. Praharaj, J. H. Han, S. Hawken, Culture and Society, 2 (2018) p. 35.

[19] R.O. Cebolla, C. Navas, International Journal of Hydrogen Energy, 44(35) (2019) p. 19067.

[20] A. Pohlmann, A. Colell, Utilities Policy, 65 (2020) p. 101066

[21] J. Horbach, C. Rammer, Energy Policy, 121 (2018) p. 404.

[22] T. Alam, M. A. Khan, N. K. Gharaibeh, M. K. Gharaibeh, Big Data for Smart Cities: A Case Study of NEOM City, Saudi Arabia. In: Smart Cities: A Data Analytics Perspective. Lecture Notes in Intelligent Transportation and Infrastructure (2021). 